\title{
La retórica hoy: Holzapfel y Perelman
}

\author{
Rhetoric today: Holzapfel and Perelman
}

ínigo Álvarez (ialvarezg@uchile.cl), Facultad de Filosofía y Humanidades, Universidad de Chile (Santiago, Chile) ORCID: 0000-0002-0001-1493

\begin{abstract}
From the analysis of Perelman by the philosopher Cristobal Holzapfel about the new rhetoric and on rhetoric itself, we can help but ask where lives the usefulness of rhetoric today. One sensible answer connects us with the sophists and the humanists' period, for whom language was a powerful tool to change the world. Nevertheless, Holzapfel calls about the importance of rhetoric today in the construction of the world, in more or less the same way we saw in the sophists and the humanists' period. The main argument of this essay is that it makes sense to talk about rhetoric today, as Holzapfel does, because it is a medium to make a projection of the world and because it may be a good moment to propose a projection of a different world; a projection where need to have a full audience to change and take down what exists today and what we don't like as such.
\end{abstract}

Key words: rhetoric, argumentation, Perelman, Holzapfel, sophists, humanist.

\section{Resumen}

Al leer el análisis del filósofo Cristóbal Holzapfel sobre la nueva retórica de Perelman y sobre la retórica en sí misma, no podemos evitar preguntarnos dónde reside la utilidad de la retórica hoy. Una respuesta sensata nos conecta con el periodo de los sofistas y el de los humanistas, en los que el lenguaje era una poderosa herramienta para cambiar el mundo. Sin embargo, Holzapfel llama la atención sobre la importancia que tiene hoy en día la retórica en la construcción de nuestro mundo, más o menos del mismo modo que vemos en los periodos de los sofistas y los humanistas. La tesis de este ensayo es que sí tiene sentido hablar hoy de retórica, como hace Holzapfel, porque es el medio para realizar una proyección de mundo y porque tal vez este sea un buen momento para proponer una proyección de un mundo diferente; una proyección para la que necesitamos contar con un auditorio nutrido para cambiar y en definitiva abatir lo que hay y lo que no nos gusta.

Palabras clave: retórica, argumentación, Perelman, Holzapfel, sofistas, humanistas.

\section{Introducción}

En el año 2015 se publicó la obra del filósofo Cristóbal Holzapfel Argumentación y proyección de mundo, en la que se abordan variados asuntos en torno al tema de la argumentación y la retórica, en especial, la nueva retórica de Perelman.

Desde el comienzo advierte el autor que lo que se busca es "explorar el nexo entre argumentación y proyección del mundo" (Holzapfel 2015:13), es decir, se busca ver de qué manera "proyectamos el mundo sobre la base de la argumentación o, mejor todavía, cómo proyectamos argumentativamente el mundo" 
(Holzapfel 2015:13). Y dado que el mundo no es el cosmos, sino la realidad humana que se construye sobre él, podríamos decir que lo que se pretende en este libro es ver cómo se proyecta nuestro mundo; que es, sin duda, nuestro, pero que es al mismo tiempo el mundo individual y propio de cada uno de nosotros; que es, por tanto, mi mundo, a la vez que es también el mundo de los otros: porque ni es posible una construcción propia aislada (pues necesitamos a los demás para construir y para mantenernos); ni cabe recibir de los demás una construcción hecha sin adicionarle algo propio (pues recibir es también, digámoslo así, manipular, esto es, interpretar, adherir lo propio y cercenar lo ajeno). En definitiva, este mundo mío, lo que yo considero la realidad, es (en realidad) también nuestro mundo, un mundo social. $Y$ en ese mundo social nos hacemos (o nos hacen), principalmente a través del lenguaje.

En La construcción social de la realidad Berger y Luckmann han destacado precisamente esta función principal que le cabe al lenguaje en la construcción del mundo: "La realidad de la vida cotidiana se presenta ya objetivada, o sea, constituida por un orden de objetos que han sido designados como objetos antes de que yo apareciese en escena. El lenguaje usado en la vida cotidiana me proporciona continuamente las objetivaciones indispensables y dispone el orden dentro del cual éstas adquieren sentido y dentro del cual la vida cotidiana tiene significado para mí" (Berger y Luckmann 1984:39). Los objetos de mi mundo son, pues, mi realidad, es decir, la realidad, porque otros que estaban antes que yo así lo construyeron, por cierto, a través de ese sistema de símbolos que es el lenguaje: "La vida cotidiana por sobre todo es vida con el lenguaje que comparto con mis semejantes y por medio de él" (Berger y Luckmann 1984:55). El lenguaje, por tanto, hace mi mundo (social y natural) y me permite conocerlo como "verdad objetivamente válida" (Berger y Luckmann 1984:89), que puedo compartir con y transmitir a otros. En palabras de estos autores: "El lenguaje realiza un mundo, en el sentido de aprehenderlo y producirlo" (Berger y Luckmann 1984:193).

Pues bien, Holzapfel está apuntando a estas mismas ideas cuando se refiere a la proyección argumentativa del mundo. Sobre lo que hay, sobre el cosmos, se construye mundo. A través de la argumentación (como se dice en el título) y también (quizá sobre todo) a través de la conversación, que es ajena a la disputa y al objetivo de decir la última palabra, y que es el "complemento infaltable" de la argumentación (Holzapfel 2015:15). Dicho sea de paso, es precisamente este olvido de la conversación lo que el autor echa en falta en el Tratado de la argumentación de Perelman y Olbrechts-Tyteca o en Los actos de habla en las discusiones argumentativas de Van Eemeren y Grootendorst.

Como adelantábamos al comienzo, los asuntos que se abordan en el libro son variados. Se habla allí de la obra Retórica (de 1976), que dirigió Helmutt Geissner; del libro, más actual, de Rodrigo Valenzuela con el mismo título; del principio de razón suficiente de Leibniz; de la relación de la retórica con la lógica y con la formación de una comunidad democrática; y se habla sobre todo de la obra de Perelman y OlbrechtsTyteca, ya mencionada, Tratado de la argumentación (de 1958). En relación con esta obra, Holzapfel trata de los problemas que plantean la constitución del auditorio; de los lugares comunes (de cantidad, de cualidad, de orden, de lo existente, de la esencia, de la persona); de las figuras (de elección, de presencia, de comunión); de los argumentos en curso; de los argumentos de fondo (enlaces de sucesión y enlaces de coexistencia); o de los argumentos basados en el ejemplo, en la ilustración y en el modelo. Esta podría ser una presentación panorámica muy breve de los asuntos que se presentan en la obra. Pero su importancia no está en esta variedad. En definitiva, la cuestión no es ver cómo el autor trata de tales o cuáles figuras, lugares comunes o argumentos. Reducir la retórica a esto sería hacerle un flaco favor al autor, desde luego, y a la retórica misma. Si así hiciéramos, estaríamos ofreciendo un arte vacuo, que consistiría en un conjunto de fórmulas o técnicas más o menos ingeniosas, pero vacías de contenido y de fundamento. $Y$ puesto que considero que la retórica no es (o no es solo) eso, creo que es más importante preguntarse por 
qué un filósofo como Holzapfel decide rescatar una obra de hace casi seis décadas. Y la respuesta no es, por supuesto, para recordarnos una lista de fórmulas.

Afirma el autor del prólogo a la edición española de la obra de Perelman y Olbrechts-Tyteca, que "para quienes la verdad puede surgir de la discusión y el contraste de pareceres, la retórica será algo más que un simple medio de expresión, un elenco de técnicas estilísticas, como la consideran aquellos para quienes la verdad es fruto de una evidencia racional o sensible" (González 1989:7). Y, en efecto, históricamente vemos cómo la retórica ha sido considerada una mera colección de fórmulas y se ha marchitado en las épocas en las que la verdad se ha defendido como algo único, objetivo o evidente, y, en cambio, ha florecido en los periodos en los que se ha considerado que la verdad es fruto de la construcción humana. Los primeros periodos suelen caracterizarse por un cierto autoritarismo, dogmatismo o elitismo, mientras que los segundos suelen ser periodos en los que las sociedades se democratizan, por decirlo de algún modo, se abren al intercambio y a la pluralidad. Y habría que preguntarse ¿por qué (o para qué) entonces la retórica hoy? Pienso que la respuesta podría remitirnos a dos periodos en los que la retórica recupera su importancia, se reafirma, surge (o resurge) y se instala en el hacer filosófico de la época: el periodo de los sofistas y el periodo de los humanistas (no es casual, por cierto, que el libro de Holzapfel comience precisamente con el apartado "La retórica y los sofistas").

\section{La retórica en el periodo de los sofistas y en el de los humanistas}

El primero de ellos nos remonta a la Grecia del siglo $V$ a.C. y a esos pensadores que se suelen denominar habitualmente los sofistas, referidos de este modo, en grupo, como si todos dijeran lo mismo y de la misma manera (bien se puede entender esto como una forma de minusvalorar a estos filósofos (por desconocimiento o de propósito), de manera similar a como se subestima la retórica, que ellos impulsaron; algo que se muestra también en expresiones del tipo "eso son sofismas" o "lo que dice aquel es pura retórica", por no mencionar el verbo sofisticar, es decir, adulterar o falsear algo, cuyo participio pasivo no deja de evocar de algún modo esta idea).

En cualquier caso, sin necesidad de abordar un estudio detallado de su mundo y sus doctrinas, bien podemos destacar lo siguiente. Para empezar, hay que recordar que los sofistas fueron criticados no solo por el hecho de cobrar por sus enseñanzas, sino también (y sobre todo) por haber desdeñado las verdades objetivas y haber enseñado, se decía, a defender cualquier opinión sin importar el contenido de lo que se sostenía. Tal crítica no es, probablemente, cierta. Entre otras razones porque es algo muy diferente enseñar a defender las opiniones propias, o sea, enseñar retórica, y defender de hecho cualquier opinión o, lo que vendría a ser lo mismo, no defender ninguna. $Y$, ciertamente, los sofistas defendieron muchas ideas porque las consideraban correctas (y no esas y sus contrarias al mismo tiempo). Defendieron, por ejemplo, la contraposición entre la physis y el nomos; la igualdad de los seres humanos; la idea del contrato social; la democracia; el derecho del más fuerte; etc., y si lo hicieron fue porque consideraban que eso era lo adecuado y no por mero azar o porque diera igual eso o cualquier otra cosa. Protágoras dice por ejemplo (en el diálogo platónico del mismo nombre) que él enseña "el arte prudente de gobernar cada uno su casa en particular, y en lo que respecta a las cosas públicas [enseña a] formar el talento que lleva a conducirlas a la perfección mediante palabras y actos" (Platón 1938:51). No, por tanto, cualquier cosa, sino lo prudente y lo perfecto.

Pero fuera lo que fuera lo que defendieron unos u otros, que fue variado, ciertamente hay algunos aspectos comunes. Para empezar, sus reflexiones se enmarcan en el campo de la filosofía política (son reflexiones sobre el origen de la ciudad, sobre el origen y el contenido de las leyes, sobre la legitimidad del 
poder o, en términos generales, sobre la ordenación adecuada de la sociedad). Y lo que defendieron lo defendieron con un objetivo práctico: toda esa reflexión política (que aparece cuando y porque se dan las condiciones propicias para ello -culturales, religiosas, sociales, etc.-) tiene sentido porque de lo que se trata es de hacer; esto es, de participar en la construcción política de la ciudad. Y es aquí donde cobra importancia la retórica. Se trata de participar en la construcción política de la ciudad no descubriendo verdades objetivas y eternas al estilo de Platón, sino ofreciendo opiniones razonables, puntos de vista plausibles, planteamientos útiles, que generen una adhesión suficiente entre los destinatarios; no sometiendo a los demás con la verdad indubitable e indiscutible, sino persuadiéndoles de que lo que se dice es lo suficientemente atractivo como para merecer su apoyo.

Es precisamente este desconocimiento de las verdades objetivas, de las esencias, lo que provoca el rechazo de Platón. Si, en términos platónicos, la verdad es la verdad, tanto da que sea plausible, atractiva o útil (que son características que, en todo caso, aparecen por añadidura). La verdad lo es porque lo es, y ahí acaba la cuestión. Y lo que podemos hacer al respecto es conocerla y transmitirla, pero nunca manipularla o crearla. Para Platón, el contraste entre los dos planteamientos es absoluto. En el Gorgias, dedicado precisamente a la retórica, el mismo Gorgias se define como maestro de retórica, esto es, maestro de ese saber que permite al hombre ser libre y dominar a otros, persuadiéndoles mediante discursos: "El orador es capaz [...] de hablar contra cualquier adversario y sobre cualquier punto de tal modo, que convenza a quienes le escuchan mejor que otro cualquiera y, como es lógico, obtener gracias a su arte todo cuanto quiera" (Platón 1938:154).

Para Sócrates, en cambio, las cosas son muy distintas: los sofistas, sostiene, son ignorantes que engañan a ignorantes, y no son maestros de ningún arte, sino de una mera práctica dedicada a la adulación, lo mismo que la cocina o la cosmética, a las que les basta con preocuparse de la apariencia y no de la verdad (como la medicina o la gimnasia). De nada sirve que, respecto de su arte, Gorgias aclare que "como de todas las armas, de la retórica hay que usar con justicia" (Platón 1938:154). El juicio de Sócrates es radical: "La retórica, Pólux, no puede en modo alguno servirnos para nada" (Platón 1938:197); y añade más adelante: "En lo que al hombre que no piensa jamás en cometer injusticias, no veo por parte alguna su utilidad" (Platón 1938:198). Su conclusión es precisa: "Hay, pues, dos clases de elocuencia política: una de ellas es una pura adulación, y por tanto, una cosa despreciable; la otra, por el contrario, es hermosa. Esta es aquella que se esfuerza por mejorar las almas de los ciudadanos procurando siempre lo bueno, guste 0 no guste al auditorio" (Platón 1938:239).

Es claro, por tanto, que para alguien como Sócrates o Platón, que defienden la existencia de una verdad objetiva, indiscutible, racional, que no está a disposición del ser humano, todo lo que atente contra esta idea se convierte en algo despreciable y rechazable. Si la verdad es una ¿para qué se necesita la opinión del auditorio?, ¿qué añade de valor el que muchos o pocos estén de acuerdo? De lo que se trata, también en política, es de descubrir e implantar la verdad, es decir, la justicia; no de entablar un diálogo con vistas a alcanzar un acuerdo. La verdad no sabe de acuerdos; es lo que es. Y si el auditorio no está de acuerdo, tanto peor para el auditorio. He ahí, según Platón (y Sócrates) el disparate de los sofistas: el de pretender que la verdad depende de nosotros (la posición de Aristóteles, por cierto, no es muy diferente, pues también para él la verdad se descubre en las esencias y no está a disposición del ser humano; no se construye; no depende de opiniones o interpretaciones subjetivas. Y solo si la técnica en que consiste la retórica se subordina a la verdad, tendrá algún valor).

Lo interesante del planteamiento de los sofistas es que el abandono de la noción de una verdad objetiva, absoluta e independiente de los seres humanos abre la puerta precisamente al relativismo y a la 
subjetividad. Que el hombre es la medida de todas las cosas, como dijo Protágoras, significa, en definitiva, que las cosas se hacen relativas al hombre. Esto es, que no existe una forma más allá de las cosas o una esencia en las cosas, es decir, una verdad, que el ser humano puede descubrir a través de su razón pero que no puede, digámoslo así, manipular. Muy al contrario, lo que hay es el ser humano que se acerca a las cosas, que las conoce a través de su experiencia y respecto a las cuales construye (que no descubre) una verdad; es decir, una verdad que es suya y no de las cosas; una verdad que, por lo tanto, está a su disposición. No significa esto, por supuesto, que esta verdad sea producto del capricho sin más. Pero sí que esta verdad es la verdad del hombre (de los seres humanos); que es, en suma, su verdad.

Por otro lado, no sería posible (o sería extraordinariamente difícil) construir esa verdad sin el lenguaje. Porque nombramos las cosas, porque nos comunicamos, porque hablamos, somos capaces de hacer que las cosas sean algo para nosotros. Para cada uno de nosotros considerado individualmente, y para el nosotros que se refiere a un grupo (que, por supuesto, se forma con cada uno de los miembros considerados individualmente).

El sofista es, precisamente, el llamado a enseñar ese arte de la palabra; el llamado a educar al discípulo y ejercitarlo en la técnica del hablar bien para hacer bien; en la técnica del hablar bien para hacer valer frente a otros el punto de vista propio, para participar de la manera más adecuada, más eficaz, en la construcción común de la verdad humana. Si, frente a Sócrates, Platón o Aristóteles, la verdad es, como decíamos, relativa a los seres humanos y se construye a través de la palabra, necesitamos aprender un buen uso de la palabra para alcanzar una buena verdad, esto es, una verdad verdaderamente útil para nosotros.

Estamos hablando de la verdad en términos generales, pero estamos hablando sobre todo de la verdad en el ámbito político. Donde con mayor claridad se puede apreciar que la verdad es relativa a los seres humanos es justamente en el ámbito de la política, en la tarea de construir y ordenar la ciudad. Si recordamos de nuevo a Protágoras, podemos ver que, en definitiva, esta verdad política no es una réplica de la naturaleza, sino una construcción humana artificial, es decir, una construcción proveniente del arte, del arte de la palabra, que involucra la participación y el debate con otros. En otros términos, la defensa de esta función de la palabra en la construcción de la verdad, sobre todo en el ámbito político, es (al menos en el caso de Protágoras) la defensa de un punto de vista democrático.

Es difícil decir por qué exactamente surge una corriente como ésta en este momento. Y es muy probable que varios elementos hayan intervenido de consuno, sin que podamos decir en qué sentido o con qué fuerza incidió cada uno de ellos (el contacto con otras sociedades, las victorias militares, los cambios políticos y sociales, particularmente el desarrollo de la democracia en Atenas, etc.). Sea lo que sea de este debate, interesa destacar este último elemento. Guthrie se ha referido a ello afirmando que "el desarrollo de la democracia iba creando la demanda a la que los sofistas pretendían servir en su calidad de educadores profesionales. El camino del éxito político estaba abierto para cualquiera, con tal de que tuviera ingenio y entrenamiento para superar a sus competidores. [...] Para este propósito lo primero que hacía falta era dominar el arte del bien hablar capaz de persuadir..." (Guthrie 2005:31-32). Es indiferente en estos momentos lo que defendieran. Lo que interesa destacar ahora es que esa defensa se propugnaba a través de la palabra y que tenía sentido plantear en estos términos la cuestión porque se daban las condiciones propicias para ello. La retórica, pues, se nos aparece como el instrumento eficaz cuando se trata de construir un mundo (o de proyectar un mundo, como diría Holzapfel), el mundo humano, en comunión y en comunicación con otros. La retórica se nos representa como la herramienta adecuada, necesaria, cuando nos vemos en la situación de hacer mundo; cuando las cosas no nos vienen dadas o 
impuestas por ninguna autoridad; cuando no las descubrimos sin más, sino que las tenemos que construir; cuando, en fin, nos vemos obligados a contar con los otros; cuando nos vemos obligados a considerar su manera de ver y de hacer; cuando, lo queramos o no, nos afecta y nos importa su opinión (pues no podemos hacer mundo en solitario).

El otro periodo en el que la retórica resurge es el periodo del Renacimiento. Los protagonistas fueron los llamados humanistas, es decir, los dedicados a la enseñanza, al cultivo de las humanidades.

No podemos entrar en este momento en el debate historiográfico acerca de cuándo, cómo, dónde y por qué se produce este proceso de cambio entre el mundo medieval y el mundo moderno, ni podemos detenernos en la riqueza de planteamientos que se generan en el seno del movimiento humanista. En todo caso, si no somos demasiado rigurosos podemos ofrecer algunas ideas generales. Lo que se conoce como humanismo (desde principios del XIX), comenzó a desarrollarse en la Italia del siglo XIV. Quizá no se pueda en rigor decir que fue un movimiento filosófico, pues se trataba fundamentalmente de un movimiento de corte literario, pero, por otro lado, traspasó los límites de lo meramente literario y fue también algo más. Los humanistas se preocuparon de la gramática, pero también de la historia o de la ética. En todo caso, fueran cuales fueran sus objetos de estudio, se afanaron en defender un método de conocimiento nuevo, un método crítico con las formas de conocer y de hacer de su época, que para ellos ya era (o empezaba a ser) una época pasada.

En efecto, nos encontramos en este momento en la gestación de una nueva época, que es también el momento del deceso de otra. Por supuesto, estamos hablando tanto de una continuidad como de un cambio. Estamos en el comienzo de la transición de la Edad Media a la Edad Moderna, en la que se puede apreciar, decíamos, el fin de un modo de entender la vida y el mundo y el nacimiento de un modo nuevo, que crece sobre (y gracias a) la muerte del anterior. Ciertamente en el Renacimiento hay un renacer de lo antiguo, de Grecia y, sobre todo, de Roma; pero, por otro lado, no habría sido posible ese renacer si la cultura antigua hubiera muerto y se hubiera perdido definitivamente, cosa que no ocurrió. Tendría que haber sido tal vez un resucitar (algo que probablemente no habría podido tener lugar). Pero no se trató de resucitar, sino de renacer, que es tan extraño como resucitar, pero que no evoca la idea de algo que ha cesado, que ha muerto, sino más bien la idea de algo que comienza de nuevo.

Es verdad que, como sostiene Baron, "el mundo cívico de Roma estuvo virtualmente olvidado durante siglos" (1993:92), pero, a pesar de todo, en absoluto se había perdido por completo el vínculo con la antigüedad. En palabras de Arnold, no hubo en la Edad Media "una total interrupción de las tradiciones de Grecia y Roma" (1949:26) (para empezar, al emplear el latín como lengua se asumía, en buena medida, toda la visión del mundo romana); y porque se conservó esa cultura antigua (mejor o peor, esa es otra cuestión) pudo ser recuperada en el Renacimiento; porque no estaba muerta sino desperdigada, deslavazada y, en algún sentido, olvidada, no hubo que pensar en una resurrección, aunque sí fue necesario hacerla renacer, buscando lo extraviado y propagando una cultura que hasta entonces había sido patrimonio de los pocos (los clérigos y los sabios). Los humanistas son los que promueven esta vuelta a la antigüedad, que no es, sin más una repetición, sino una renovación que tiene que hacerse sobre y contra lo que hay (sobre y contra lo medieval, sobre y contra el saber escolástico, sobre y contra las universidades). Fueron, muchos de ellos, maestros ambulantes, guías de jóvenes, educadores de príncipes, y abanderados de un método nuevo, cuya expansión se vio favorecida, entre otras causas, por el apoyo económico y la protección de algunos gobernantes y otros personajes poderosos. 
Lo interesante de este movimiento humanista, para nosotros, es que la retórica ocupó un lugar primordial en sus planteamientos. Uno de los rasgos característicos del Humanismo (sobre todo en sus primeras manifestaciones) es su deseo de distanciarse y diferenciarse de los modos de expresión de la época escolástica. Frente al latín tosco de los escolásticos, los humanistas defienden un uso culto, airoso, elegante. Frente al peso otorgado a la gramática y a la dialéctica en la época anterior, los humanistas defienden el papel fundamental de una retórica que es, que debe ser, complemento tanto de la gramática como de la dialéctica. No se trata, pues, solo de expresarse con corrección y de argumentar de manera adecuada (y por ese orden); se trata también de expresarse con belleza, con donaire, con pureza de formas y elegancia. Se trata de abandonar el modo de hacer anterior (y ya antiguo); ese método lógico (dialéctico) que se abocaba a la interpretación de los grandes textos (fundamentalmente de Aristóteles) y que había producido una literatura escolástica, que se consideraba ya acabada e inútil para un nuevo tipo de vida y de visión del mundo (lo que se gesta ahora es "un nuevo método de pensar y de crear, de querer y de obrar" Adorno 1955:18). Se hace entonces necesario volver la mirada a las fuentes antiguas, a los textos latinos originales, a las fuentes primigenias del idioma. Y no es casual que Cicerón se convierta (con mayor o menor peso y admiración según el momento), en el ejemplo (o en uno de los ejemplos) a seguir (y sirvió como modelo tanto para una vida reflexiva y apartada del tráfago social o político, como para la vida del que participa en el devenir de la ciudad).

Este bien decir, este decir elegante, elocuente, se propugna en todas las disciplinas, en la historia, en la ética, en la religión y también, quizá sobre todo, en la política. La elocuencia, dice Burckhardt, se hace "ornamento y elemento necesario de una existencia elevada" (2005:279), y los virtuosos de la palabra (por cierto, con independencia de su nivel social) aparecen por doquier, en actos civiles, políticos o religiosos. Pero interesa ahora resaltar esta relación de la retórica con la vida política, a la que se han referido tantos autores. Por ejemplo, en el artículo de González sobre la definición del humanismo, leemos: "[los humanistas] se dieron a la búsqueda de un método capaz de sistematizar el mundo de los conocimientos optativos, cuestionables, de los juicios inciertos [...] [de] un saber que ayudara a secretarios, administradores públicos y gobernantes en sus deliberaciones políticas, que rara vez tenían el carácter de deducciones irrefutables" (González 1989:59). Y un poco más adelante concluye: "Humanista era aquel que, por haber estudiado las letras humaniores, se volvía apto para la vida propiamente humana: la vida activa en la ciudad" (González 1989:61). Si esto es así, podemos ver de nuevo cómo el resurgir de la retórica tiene que ver con la necesidad de dotarse de una herramienta eficaz para la vida política (en el sentido más amplio de la palabra); para una vida política que exige dialogar con otros y convencerlos; es decir, para una vida política en la que no se puede prescindir de la cooperación y de la anuencia de los demás (lo que no significa que siempre se desarrollara de este modo).

Como se sabe, una de las tesis de Burckhardt es que la particular situación de las repúblicas y tiranías italianas propició el nacimiento de una nueva sociedad y de un nuevo tipo de ser humano. Mientras que en la época que termina, los seres humanos se conciben como miembros del grupo que los contiene, en la época que está naciendo en Italia "se despierta una forma nueva y objetiva de observar y tratar el estado y en general las cosas de este mundo, y a su lado, y con el mismo ímpetu, se levanta también lo subjetivo; de modo que el hombre se convierte también en individuo provisto de un espíritu y se reconoce a sí mismo como tal" (Burckhardt 2005:175). Pues bien, es ese individuo provisto de un espíritu, ese individuo libre y desligado de su grupo de referencia, el que es capaz de destacarse frente a los otros, de desarrollar su particular modo de hacer y de ser. Algo que es posible porque se dan las circunstancias políticas y sociales propicias para ello. Y algo que se logra en variados ámbitos del arte y con diversas técnicas, pero sobre todo, a través de la palabra. 
También ahora la retórica tiene valor en tanto instrumento práctico que se precisa para encontrar el lugar que uno cree merecer, para alcanzar el poder y la fama a la que se aspira, para acotar el espacio propio en el mundo. El desarrollo del humanismo del Renacimiento y el florecimiento de la retórica son un excelente ejemplo de esta proyección de mundo de la que habla Holzapfel. El nuevo ser humano, la nueva sociedad, el nuevo mundo se va construyendo con palabras que devienen hechos.

\section{La retórica hoy}

Podríamos retomar en este momento la pregunta que nos hacíamos anteriormente: Si la obra de Perelman y Obrechts-Tyteca tiene casi sesenta años, ¿qué sentido tiene hacerla presente? Creo que la respuesta puede venir sugerida por lo que hemos dicho acerca de los sofistas y de los humanistas. En ambos periodos se presenta el arte de la palabra, la retórica, como el instrumento pertinente para construir una realidad nueva; una realidad, decíamos, que no se descubre sin más, que no viene impuesta por la divinidad o por la autoridad indiscutible. Una realidad que debe hacerse con otros.

En ambos periodos se ha podido hablar de crisis, de cambio, de fin de una época y comienzo de algo nuevo. Es posible que los periodos de crisis fomenten la necesidad de algo nuevo y el anhelo de construirlo; pero también es posible que el anhelo por algo nuevo sea lo que propicie la crisis y promueva el cambio. Si esto fuera así, bien podríamos pensar que el filósofo Holzapfel hace esta defensa de la retórica, de la argumentación, porque nos está invitando precisamente a constituirnos en motores de un cambio; es decir, porque siente la necesidad de que produzca algo nuevo (y que se produzca en común y a través de la palabra). Me parece que aparecen estas ideas cuando Holzapfel nos habla de la función de la retórica como argumentación, y no tanto como persuasión. Cuando la retórica se dirige a la persuasión, cuando su meta es simplemente convencer, se ve achatada y apegada a lo que hay, a lo común, a lo conocido, pero entonces difícilmente puede ser motor para el cambio (se entiende entonces, dice Holzapfel, su desvirtuación y desacreditación, porque se ha acomodado "en la cercanía de los poderes fácticos" 2015:103). Pero en sentido contrario, cuando es argumentación y no mera persuasión, se preocupa por la construcción del auditorio y se dirige a lograr acuerdos que tengan como base "la reciprocidad y el mutuo reconocimiento de interlocutores que se validan entre sí" (Holzapfel 2015:101). Y es entonces cuando puede tener una función en el desarrollo de la democracia; cuando puede constituirse en un motor para el cambio; cuando puede ser no solo el producto de una crisis, sino también una de sus causas; cuando, como dice el autor, "también tiene en sus manos la posibilidad de enfrentar esos códigos [los códigos de la cotidianidad], pues la argumentación da lugar a la posibilidad de la contraargumentación, y junto con ello del diálogo y la comunicación" (Holzapfel 2015:102-103).

Por tanto, si tiene sentido hablar hoy de retórica, como hace Holzapfel, lo tiene, primero, porque es el medio para realizar esa proyección de mundo; $y$, segundo, porque tal vez este sea un buen momento para proponer una proyección de un mundo diferente; una proyección para la que necesitamos contar con un auditorio nutrido para cambiar y en definitiva abatir lo que hay y lo que no nos gusta.

Se ha dicho que la propuesta de Perelman es un intento por rehabilitar la retórica dentro de la filosofía (la nueva retórica, dice González, aspira "a ser una disciplina filosófica moderna con dominio propio" 1989:17); un intento por desarrollar esa lógica de lo razonable (que se sitúa entre la deducción indiscutible y la arbitrariedad irracional) y por construir, en suma, una filosofía permanentemente abierta al debate. Y ciertamente su campo de acción está en la filosofía; pero también está más allá. Los mismos autores del Tratado, al hablar del ámbito de desarrollo de la nueva retórica, se refieren al estudio de "los medios de prueba de los que se sirven las ciencias humanas, el derecho y la filosofía; [...] las argumentaciones 
presentadas por los publicistas en los periódicos, por los políticos en los discursos, por los abogados en los alegatos, por los jueces en los considerandos, por los filósofos en los tratados" (Perelman y OlbrechtsTyteca 1989:42-43). No es de extrañar que reconozcan que su campo es inmenso.

Pero puestas así las cosas, podemos preguntarnos ¿qué es nuestro mundo sino precisamente todo esto?, ¿qué es sino el resultado de los debates que se tercian en este terreno acerca de cómo queremos vivir? Si esto es así, no es necesario decir mucho más para destacar la función primordial que le cabe a la argumentación y a la retórica, que es nada menos que la de formar la base sobre la que se construye el mundo. El pensamiento de Holzapfel ofrece un excelente material para esta reflexión.

\section{Bibliografía}

Adorno, F. 1955. Introducción, pp. 9-111. En: L. Valla. Oraciones y prefacios. Santiago: Universidad de Chile.

Arnold, R.F. 1949. La cultura del Renacimiento. Barcelona: Labor.

Baron, H. 1993. En busca del humanismo cívico florentino. México: Fondo de Cultura Económica.

Berger, P. y Luckmann, T. 1984. La construcción social de la realidad. Buenos Aires: Amorrortu.

Burckhardt, J. 2005. La cultura del Renacimiento en Italia. Barcelona: RBA.

González, J. 1989. Perelman y la retórica filosófica, pp. 7-26. In: Ch. Perelman y L. Olbrechts-Tyteca. Tratado de la argumentación. Madrid: Gredos.

González, E. 1989. Hacia una definición del término 'humanismo'. Estudis: Revista de Historia Moderna 15: 45-66.

Guthrie, W.K.C. 2005. Historia de la filosofía griega III. Madrid: RBA.

Holzapfel, C. 2015. Argumentación y proyección de mundo. Santiago: Editorial Universitaria.

Perelman, Ch. y Olbrechts-Tyteca, L. 1989. Tratado de la argumentación. Madrid: Gredos.

Platón. 1938. Protágoras, Gorgias, Fedro. Madrid: Bergua.

Recibido el 22 Jul 2016

Aceptado el 2 Sep 2016 